\title{
PIONEER
}

VOLUME 13, Issue 2, December 2021: 213 - 226

\section{DISCRIMINATION ANALYSIS OF THE MAIN CHARACTER IN MOVIE CRAZY RICH ASIANS}

\author{
${ }^{1}$ Jimmi* \\ ${ }^{1}$ Universitas Bina Sarana Informatika, Indonesia \\ Ijimmi.jmm@bsi.ac.id \\ ${ }^{2}$ Windi Mawadah \\ ${ }^{2}$ Universitas Bina Sarana Informatika, Indonesia \\ ${ }^{2}$ windimawadah@gmail.com
}

*Corresponding author: jimmi.jimm@bsi.ac.id

Received : November 9, 2021

Revised : December 15, 2021

Accepted : December 17, $2021 \quad$ Published : December 31, 2021

\begin{abstract}
The objective of this research is to explain the types of discrimination shown by the main character in her society and to identify the effects that main character experienced after being discriminated. This research used descriptive qualitative method to analyze the movie. The subject of this paper was movie Crazy Rich Asians by Jon M Chu. The data analysis was conducted using U.S. Equal Employment Opportunity Commission theory reference. By the process of the analysis, it was that harassment, national origin discrimination, race/color discrimination, and religious discrimination were experienced by the main character. Not only that, the researchers found four types of effects experienced by a person after being discriminated, which are marginalization, disempowerment, low self-esteem and self-identity, and aggression or criminality.
\end{abstract}

Keywords: discrimination, main character, movie

\section{INTRODUCTION}

When watching a movie, people can learn the aspects of literature, such as the messages, the characterization, and also the theme or the topic implied in the movie. One of the most brought up topics in a movie is discrimination. Discrimination is the unfair or prejudicial treatment of people and groups based on characteristics such as race, gender, age or sexual orientation (American Psychological Association, 2019). There are many examples of discrimination we can find in everyday life, such as one is alienated for having a different social status or one is bullied for having a different skin color. Being 
discriminated can affect mental health. (Williams et al., 2019) explained that people who are treated badly experience psychological, mental, and social distortion.

In this research, the researchers used movie Crazy Rich Asians as the object of this research because of Rachel Chu, the main character who was discriminated by those around her. Rachel Chu is an ordinary Chinese professor who grew up in New York and received an unfair treatment because of her ethnic origin, personal appearance, and caste in the society. This research focused on analyzing the types of discrimination experienced by the main character in this movie, Rachel, and the effects of the main character experienced after being discriminated.

\section{REVIEW OF LITERATURE}

\section{Definition of Discrimination}

Discrimination is treating a few bunches of individuals as if they were less inalienably commendable than others (Smith, 2016). Discrimination may be a treatment that separates an individual or more because it is considered to have differences with others. Usually someone who discriminates seeks fault of someone whom he thinks does not meet his or her standard of living. The people who could be a victim of discrimination will consider that they are worthless because of their dissimilarity with those around them. That way, someone who discriminates can find a reason for the person who gets the discrimination to be proven that they are unequal with them.

Discrimination does not always refer to negative things. Some treatments from discrimination have positive sides that can benefit for someone who gets discriminatory treatment. (Laki, 2014) stated the act of discrimination does not always lead to things that intimidate someone or make someone unequal. Positive discrimination can make an advantage for some people who feel different from those around them. This statement is supported by (Fish \& Syed, 2019) who said that discrimination could be positive or negative. Thus, it all depends on people's perspective. A wrong perspective against people can cause injustice that is detrimental to someone. For example, a woman who is influenced by American cultures will prioritize education rather than prioritizing family welfare. 


\section{Types of Discrimination}

Subsequently, discrimination is divided into several types concurring to the object that is utilized as material for discrimination. Based on (U.S. Equal Employment Opportunity Commission, 2017), discrimination is divided into several types in the following:

a. Harassment: an unwelcome conduct that involves descendent, tint, fate, gender (including pregnancy), derivation country, period (40 or elderly), inability or genetic information

b. National Origin Discrimination: an unfair treatment for people who have just moved to a new place, and it will create a negative sight to see new people stay in new place. Anything will stare to the people who just got join or move to the new place.

c. Race/Color Discrimination: an unfair act to people for having a different appearance. This makes one feel disrespected due to their different skin color, hair color, or even culture background.

d. Religious Discrimination: an unfair act to discriminate someone based on the fate or religion only. This certainly will make someone underestimated because the believes they have.

\section{Definition of Effect}

Quoted from (Grover, 2017), effect is a positive correlation (one to one) i.e. ascertaining the cause using some scientific method, whereas influence is a partial and multiple relations between one variable with many others. In this case, what is implied by a direct correlation between two things is the relation between the causes and the results produced.

(Augustine, 2020) defined effect as an impact of a variable on the other which can either be positive or negative. Most people think that an effect is a negative thing, but for some people, the effect can be a positive thing. For example, people will be easier to communicate according to their social class that is equal to them than people whose social class is higher or lower than them. From the definition, it can be concluded that an effect is a result of a process carried out by a person that leads to certain things. An effect straightforwardly is related to the outcome, and process which can be positive or negative 
for people depends on their situation. Most people experience negative things from an effect, but some people feel positive about an effect.

\section{Types of Effect}

Discrimination has a negative effect for person who is discriminated. Based on ("Equality, Diversity and Rights in Health and Social Care," 2020), the followings are the effects of discrimination:

1. Marginalization: when someone is excluded from the part of a group or fa amily.

2. Disempowerment: having no power or being underestimated due to being less powerful than others.

3. Low self-esteem and self-identity: an act that causes individuals lose confidence, get negative treatments, and have a low social identity. This causes can bring uselessness and degradation level of life.

4. Negative behaviors: negative perspectives given by the society to people after being discriminated. Anything done will be judged negatively.

People who are discriminated are likely to feel unworthy, incapable to adjust with people around them, decreased in health, stressed, depressed, and triggered to do unexpected things.

\section{Definition of Main Character}

Generally, character is a person or others created by an author. According to (Literary Terms, 2015), a character is a figure is a necessary element in making a story. Several character elements can make the story more interesting. For example, the existence of two antagonists in one story that can lead to disputes.

Meanwhile, the main character is a character that is often seen in a story. According to (Dinangun, 2019), people who are observing a story can know the main character of the story by how often a character shows up. If a character dominates the whole content of the story, it is certain that the he/she is the main character. That statement is also supported by (Mometrix Test Preparation, 2021) that explained that a main character influences the story. This influence can be in the positive or negative way. If the main character influences in a positive way, it is called the protagonist. Otherwise, if the main character influences in a negative way, it is called the antagonist. 
In a story, people often claim that the figure in the tale is a good figure. However, the protagonist does not always control the whole story. According to (MasterClass staff, 2021), both the major figures and the good characters in story are somehow similar. For example, Maleficent who is a forest ranger turned into an evil witch after being betrayed by the king and wanted to take revenge on him.

\section{METHOD}

This is a descriptive qualitative research. According to (Lambert \& Lambert, 2013), this method should be planned to get the any data needed by researchers. The data have an important section because from the data the researchers will begin to analyze any possible answer based on the problems that have been formulated.

The objective of applying a descriptive qualitative method in this research was to describe the discriminations experienced by the main character in movie Crazy Rich Asian and the effects of the discrimination she experienced.

\section{FINDINGS AND DISCUSSION}

\section{Findings}

The researchers used a theory proposed by (U.S. Equal Employment Opportunity Commission, 2017) to categorize the types of discrimination. The four types that researchers found are harassment discrimination, national origin discrimination, religious discrimination, and race/color discrimination.

In effect of discrimination of the main character, the researchers uses ("Equality, Diversity and Rights in Health and Social Care," 2020), in the researchers point of view this theory is much relevant to the main character, faced by Rachel in the movie. The four effects that the researchers found are Marginalization, Disempowerment, Low selfesteem and self-identity, and Negative behaviors such as aggression or criminality.

\section{Harassment}

Harassment is a discriminating behavior directed at someone because of race, color, religion, or personal appearance. In this movie, the main character experienced some harassment. 


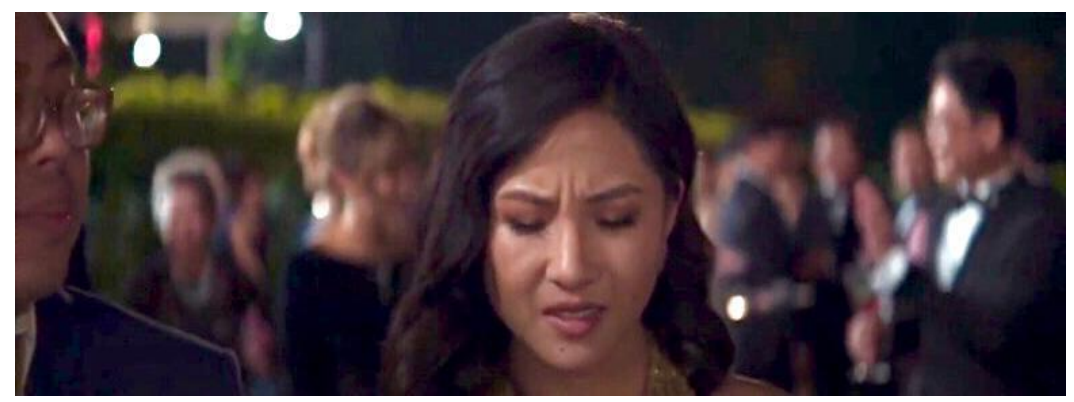

Figure 1. People were Staring at Rachel

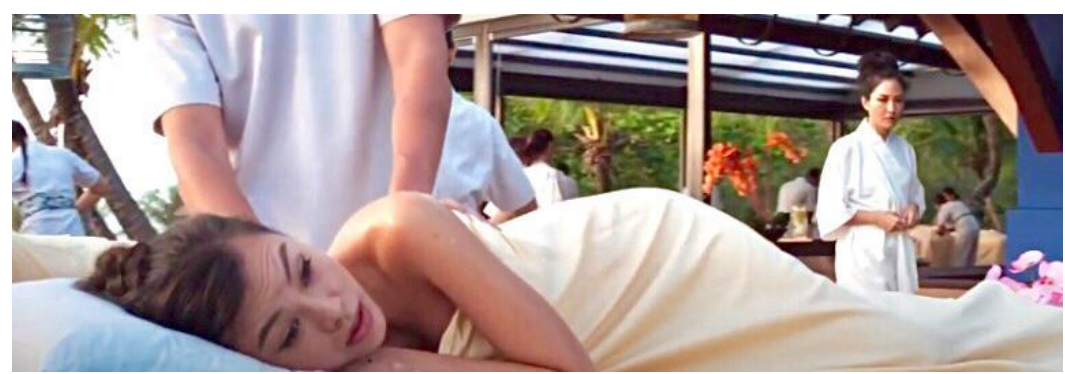

Figure 2. People were Talking about Rachel

Figure 1 shows people staring at the main character, Rachel. She could feel it and wondered why people were looking at her. People stared at Rachel because she had a striking difference from others that attracted people's attention. Figure 2 shows a woman saying that Rachel should have undergone a plastic surgery for her ordinary face to be more beautiful. This brought her to sadness and she immediately walked away into her lodging house.

\section{National Origin Discrimination}

National Origin Discrimination distinguishes a person or a group from a particular country. It also applies to a person or a group who have a different articulation when speaking, or because they show to have a particular cultural background. For example, a Chinese woman, Rachel who was raised in the United States followed the Western cultures. When she met a real Chinese person, she got a different treatment. 


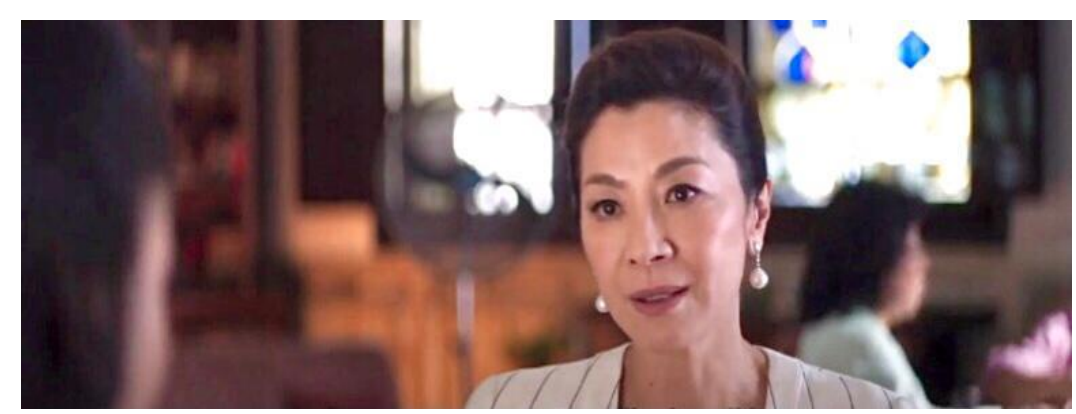

Figure 3. Eleanor Rejected Rachel as Part of the Family

This shows that the main character, Rachel who was not acknowledged as a Chinese. Eleanor insisted that Rachel was an American. Although Rachel was a Chinese, the culture that she adopted was western culture and that was unacceptable to Eleanor.

National Origin Discrimination is a sensitive matter among ethnics. For some people who have an open mind this will not be a problem if people from other ethnics. Otherwise, this is problematic for certain groups of people who have a tradition that their group must be with people who are equivalent to them. A person who adheres to a certain tradition will certainly choose a person who has a close similarity to be part of his group.

\section{Religious}

Religious discrimination is a treatment that discriminates a certain person or group based on their religion. For example, in area A, the majority of the population adheres to Hinduism, but there is a person or group of people who are Confucian living there. It is likely that that person or group of people who are Confucian will receive a different treatment from other people.

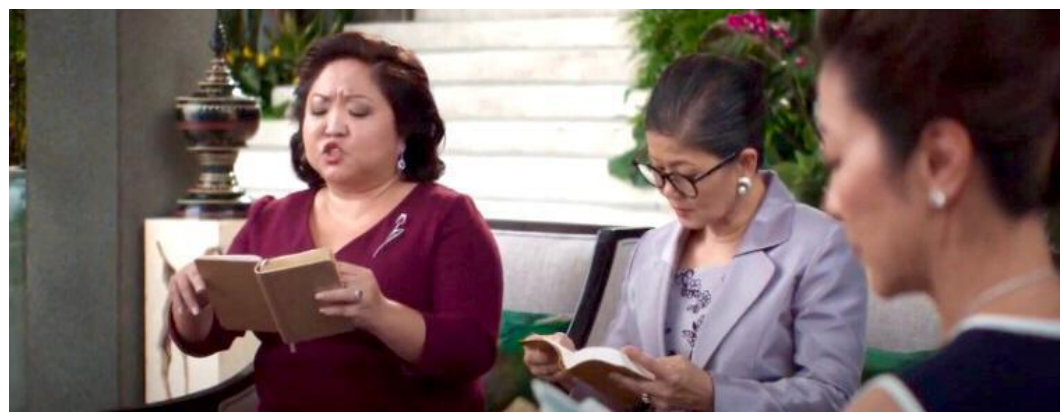

Figure 4. Praying to God

It shows the dialogue between Aunt Alix and Aunt Felicity. They alluded Rachel's religion indirectly. In fact, they had clearly never seen Rachel in person. Aunt Felix hoped that Rachel was a good Christian girl. But so far, it was not fully known what religion Rachel adhered to. This scene shows the type of religious discrimination because 
someone who did not know each other had mentioned someone's religion. If the person was not as expected, then discrimination can spread.

\section{Race or Color Discrimination}

Discriminatory behavior can be done by someone physically or verbally. A person who does not like someone for some reason is willing to do anything to get rid of the person that he or she does not like. This action can hurt the victim's feeling because of the behavior he or she does not deserve. The main character in this film also experienced some verbal discrimination, one of which was when Eleanor said that Rachel was not good enough for her family. It can be seen from Figure 5.

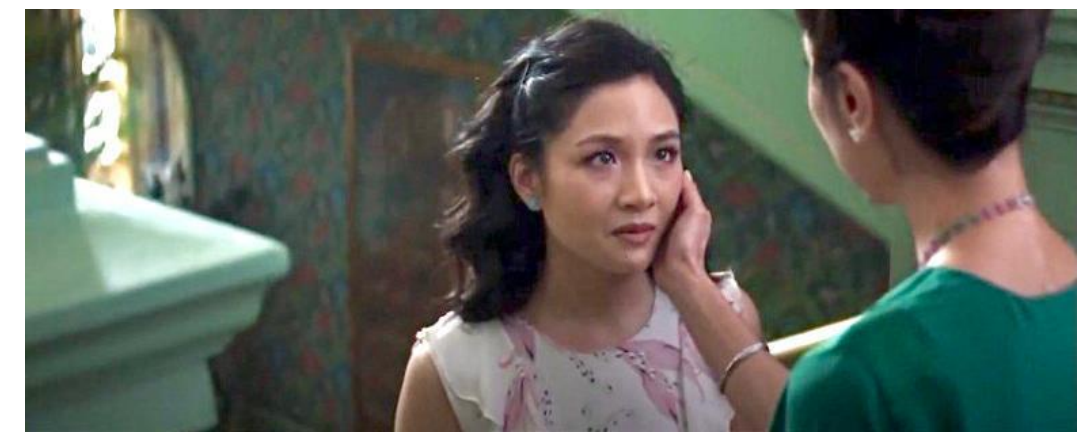

Figure 5. Eleanor Claimed that Rachel Did Not Meet Eleanor's Family Standard

Eleanor told Rachel that in the past she was not the first choice for Nick's father, nor was she the second choice. However, Eleanor tried harder, and ended up winning Ah Ma's heart. Rachel tried hard to get herself accepted into Nick's family, but Eleanor believed that Rachel would never be enough to meet Eleanor's standards. She still assumed that Rachel was not a pure Chinese becasue Rachel grew up in a country that did not adhere to Chinese traditions.

Those discriminations experienced by Rachel caused some effects. Here are the details.

\section{Marginalization}

Marginalization is a feeling that someone is no longer part of a group. Usually someone who experiences marginalization is a victim who experiences discrimination. For example, someone who is not liked by the group of people will be treated differently from others, so that the victim of discrimination feels that he or she is not part of the group 
anymore, and leaves the group. This also happens in movie Crazy Rich Asians. A woman who tried hard to be part of a group, but was still treated differently by a group.

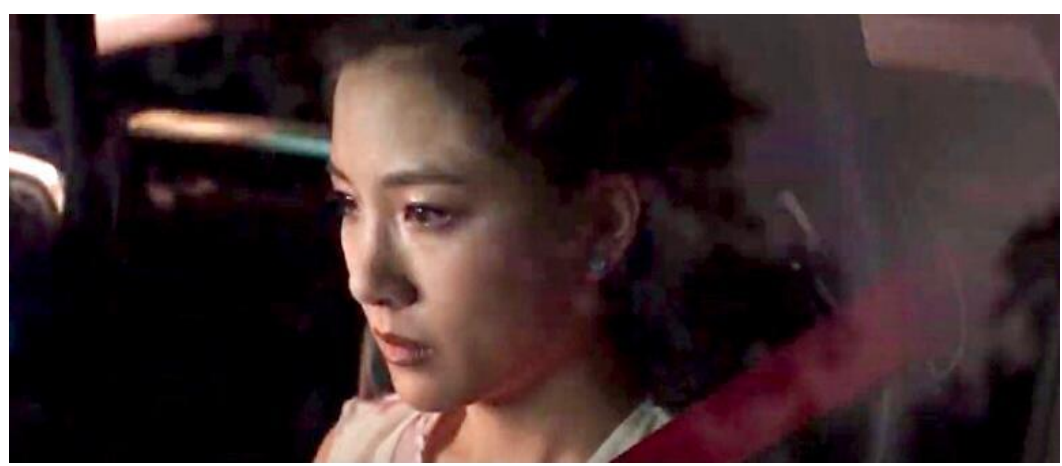

Figure 6. Rachel's Sad Expression

This shows the main character's sad expression with a blank stare and teary eyes. Discrimination can lead to marginalization for a victim. A victim who is being affected by marginalization usually thinks of words that offend him or her. This can cause erratic thoughts, and can even cause stress to the victim.

\section{Disempowerment}

A person who experiences discrimination by people in power has the effect of disempowerment on the victim. Some of the victims will fight back, but others will become increasingly helpless and because they may end up depressed, unworthy, and helpless, it could turn to great effort to get the best result. For example, the victim who is experienced treatment differently from other people will cause depression because they keep thought about the mistakes that caused them being treated differently.

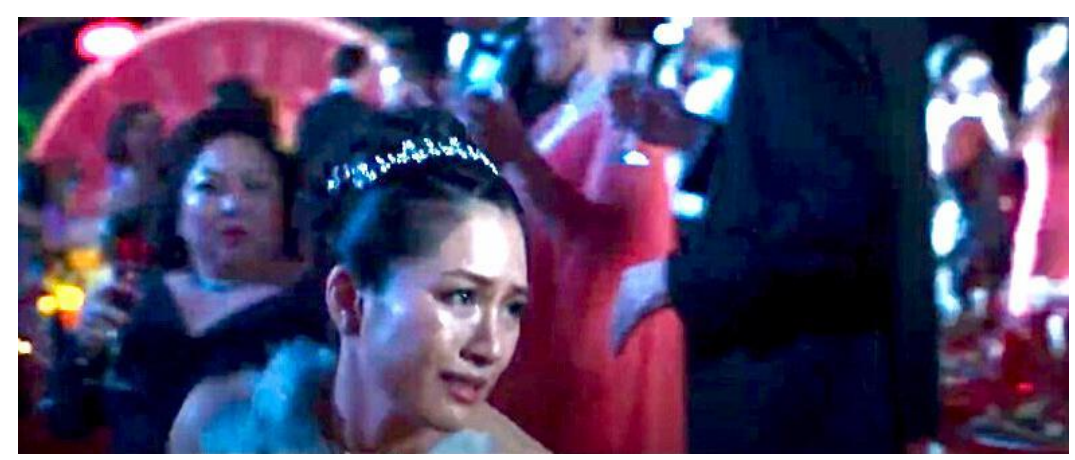

Figure 7. Rachel Tries to Find A Way Out

Rachel tried to leave the place because she was being ridiculed by the guests after Eleanor pointed out that Rachel lied about her father to Nick's family. Eleanor also said 
that her family should not have any relation with Rachel. This made her so sad then she left as soon as possible from that place. In this case, disempowerment makes a person unable to resist the treatment of others because they cannot stand their treatment. A person who experiences disempowerment also feels confused and stressed because he gets treatment that he should not get.

\section{Low Self-esteem}

Someone who experiences discrimination will feel the loss of self-confidence because being no longer useful. The victim usually think about walking out of the group. This can lead to a loss of self-confidence, and not even being able to believe in themselves. For example, a person who believes in what people say about him or her even though he or she is not like that. The victims will trust people's words more than themselves.

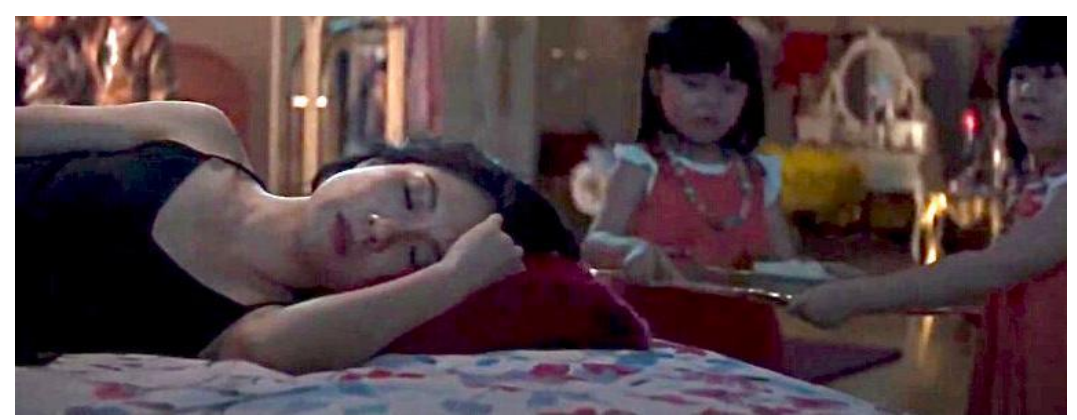

Figure 8. Rachel Felt Depressed

It shows the main character, Rachel, who locked herself in the room. Peik Lin offered her to eat, but Rachel refused. Rachel lost her confidence when Eleanor gave evidences that Rachel's mother was cheating on her husband and told her that her family did not have any relation with Rachel. Some people who cannot overcome the discrimination that they receive will feel that it is such a big deal for them and do not know how to fix it. This will cause prolonged stress and even depression.

\section{Negative Behavior}

A negative behavior such as aggression or criminality can occur because someone does not accept when getting discriminated. This causes the need to take a revenge on people who discriminate them. For example, a victim who is being discriminated verbally will fight it back by taking an action. A person who does not accept the way people treat him or her will take an action to retaliate. 


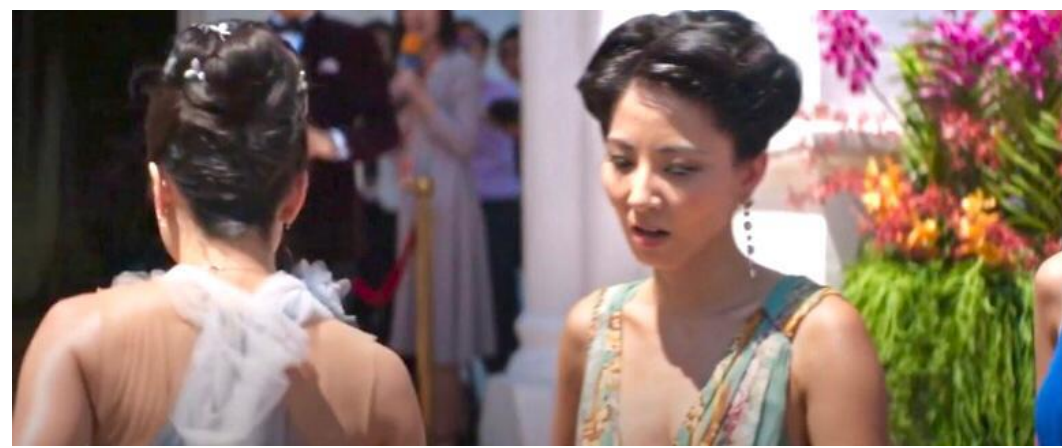

Figure 9. Amanda was Standing on Rachel's Way

This shows that Amanda who once discriminated Rachel still did not like her. Rachel to take a revenge on Amanda by saying that Amanda was on her way. A person who has an open mind will not take violence for revenge. Humiliating people in public is enough to teach someone a lesson so as not to repeat his or her mistakes.

\section{Discussion}

From the data analysis, it can be seen that the person who does the discrimination tend to seek for other mistakes on the victim of the discrimination. Therefore, the person who discriminates will take more than one actions to prove that the victims were not equal to him or her. For example, someone who does not have an attractive body, has no known family identity, and has been influenced by other cultures, will receive discrimination based on gender, genetic information, and national origin.

The discriminations experienced by Rachel were because of religious and race issues. Therefore, she was discriminated and bullied because of her being different. If we see how discrimination relates to bullying, discrimination occurs when the bullying involves issues on religion and culture. Discrimination is a form of bullying (Prasetiyo, 2012). The effects of discrimination felt by Rachel are also varied, from the feeling of being unworthy, incapable to adjust with people around her, decreased in health, stressed, depressed, and triggered to do unexpected things. These all belong to psychological impacts. These proofs are similar to the result of the research conducted by (Novitasari and Hia, 2021) and (Sirly and Novitasari, 2017) who analyzed the impacts of bullying. Both discrimination and bullying can damage the victims' mentality. In other words, any act that makes unjustified distinctions between people based on the groups, classes, or other categories to which they belong or are perceived to belong will create physical, emotional, and mental impacts to the victims. 


\section{CONCLUSIONS AND SUGGESTIONS}

\section{Conclusions}

The four discriminations that the researchers found are harassment discrimination, national origin discrimination, religious discrimination, and race/color discrimination. This proves that any kind of discrimination may happen even in a modern life and society. The effects of the discrimination experienced by the main character found are marginalization, low self-esteem, and self-identity. These all effects are dangerous as they affects someone's mental health and well-being.

\section{Suggestions}

Movie Crazy Rich Asians tells about the unaccepted person with someone who has a different background. Based on the researchers' point of view, the movie has a long duration by showing scenes of discrimination that tend to be similar. It can make the viewer to get bored easily with the long duration and less showing the climactic scene. The researchers suggest to shorten the scenes that have similarities, so that the audiences can identify the points and the messages of the movie easily.

Furthermore, the movie shows many scenes of discrimination that is advisable to be watched by viewers who are thirteen years old and above. Even if the movie does not show any violent or suicidal scenes, for some conditions, young viewers must be accompanied by adults when watching the movie. The comedy element in the movie, however, can create a pleasant atmosphere.

\section{REFERENCES}

American Psychological Association. (2019). Discrimination: What it is, and how to cope. https://www.apa.org/topics/racism-bias-discrimination/types-stress

Augustine, A. A. (2020). What is the difference betweem "influence" and "effect" in researches?https://www.researchgate.net/post/What_is_the_difference_betweem_i nfluence_and_effect_in_researches

Centers for Disease Control and Prevention. (2021). Office of Equal Employment Opportunity (OEEO). https://www.cdc.gov/eeo/faqs/discrimination.htm\#4

Dinangun, D. S. A. (2019). An analysis of expressive perlocutionary act of main character's utterances in Sausage Party Movie (2016) [UIN SUNAN GUNUNG DJATI]. http://digilib.uinsgd.ac.id/24986/ 
Equality, diversity, and rights in health and social care. (2020). OpenLearn Create. https://www.open.edu/openlearncreate/mod/page/view.php?id=153145

Fish, J., \& Syed, M. (2019). Racism, Discrimination, and Prejudice. April. https://doi.org/10.31234/osf.io/gh8kr

Grover, V. (2017). What is the difference betweem "influence" and "effect" in researches?https://www.researchgate.net/post/What_is_the_difference_betweem_i nfluence_and_effect_in_researches

Ikawati, L., Johnson, K., \& Jackson, M. (2018). Afro-American women discrimination on hidden figures - : A critical discourse analysis. Indonesian Journal of English Language Studies, 4(1), 12.

James Madula, Singgih Daru Kuncara, C. A. (2017). REBELLION AGAINST RACISM AND DISCRIMINATION IN THE MOVIES RISE OF THE PLANET OF THE APES AND DAWN OF THE PLANET OF THE APES. 1. http://ejournals.unmul.ac.id/index.php/JBSSB/article/view/680

Laki, I. (2014). The Concept of Discrimination Nowadays. Political Science, Marshall $1998,188-193$.

Lambert, V. a., \& Lambert, C. E. (2013). Qualitative Descriptive Research: An Acceptable Design. Pacific Rim International Journal of Nursing Research, 16(4), 255-256.

http://antispam.kmutt.ac.th/index.php/PRIJNR/article/download/5805/5064

Literary Terms. (2015). https://literaryterms.net/

MasterClass staff. (2021). What's the Difference Between a Main Character, Protagonist, and Hero? https://www.masterclass.com/articles/whats-the-difference-between-amain-character-protagonist-and-hero\#what-is-a-main-character

Mometrix Test Preparation. (2021). What is the Definition of a Character in a Story. https://www.mometrix.com/academy/characters/

Novitasari, N. F., Irma, N., \& Hia, A. (2021). Cyberbullying in Movie Cyberbully : an Analysis From the Psychological Perspective. Celtic: A Journal of Culture, English Language Teaching, Literature and Linguistics, 8(1), 44-64. https://doi.org/10.22219/celtic.v8i1.16393

Prasetiyo, A. (2012). Diskriminasi Karena Pilihan Ilmu, Bentuk Bullying yang Tak Disadari.

https://www.kompasiana.com/anjasprasetiyo/5517d16481331122699de317/diskri minasi-karena-pilihan-ilmu-bentuk-bullying-yang-tak-disadari

Puspita, A. (2015). AN ANALYSIS ON LANGUAGE FUNCTION OF "ENCHANTED" MOVIE SCRIPT [IAIN Tulungagung]. http://repo.iain-tulungagung.ac.id/2045/ 
Rob Allison; Brian Chanen. (2012). IB English A Language \& Literature: Course Book: Oxford IB Diploma Program Course Book. Oxford University Press.

Sirly, N. A. W., \& Novitasari, N. F. (2017). Bullying Portrayed in Mean Girls Movie: A Psychoanalysis. Pioneer, 09(2), 130-140.

https://unars.ac.id/ojs/index.php/pioneer/article/download/453/381

Smith, N. M. (2016). Basic Equality and Discrimination. In Basic Equality and Discrimination. https://doi.org/10.4324/9781315568768

St George International. (2015). How Many People In The World Speak English? https://www.stgeorges.co.uk/how-many-people-in-the-world-speak-english/

U.S. Department of Justice. (2021). TYPES OF EMPLOYMENT DISCRIMINATION. https://www.justice.gov/crt/types-employment-discrimination

U.S. Equal Employment Opportunity Commission. (2017). Discrimination by Type. https://www.eeoc.gov/discrimination-type

Victoria Legal Aid. (2019). Discrimination and victimisation. https://www.legalaid.vic.gov.au/find-legal-answers/discrimination-harassmentand-bullying/discrimination-and-victimisation

Williams, D. R., Lawrence, J. A., Davis, B. A., \& Vu, C. (2019). Understanding how discrimination can affect health. Health Services Research, 54(S2), 1374-1388. https://doi.org/10.1111/1475-6773.13222 